\title{
A concise review of the efficacy of stereotactic radiosurgery in the management of melanoma and renal cell carcinoma brain metastases
}

\author{
Peter W Hanson ${ }^{1,2}$, Ameer L Elaimy ${ }^{1,2}$, Wayne T Lamoreaux ${ }^{1,2}$, John J Demakas ${ }^{1,3}$, Robert K Fairbanks ${ }^{1,2}$, \\ Alexander R Mackay ${ }^{1,4}$, Blake Taylor ${ }^{1,2}$, Barton S Cooke ${ }^{1}$, Sudheer R Thumma ${ }^{1,2}$ and Christopher M Lee ${ }^{1,2,5^{*}}$
}

\begin{abstract}
Melanoma and renal cell carcinoma have a well-documented tendency to develop metastases to the brain. Treating these lesions has traditionally been problematic, because chemotherapy has difficulty crossing the blood brain barrier and whole brain radiation therapy (WBRT) is a relatively ineffective treatment against these radioresistant tumor histologies. In recent years, stereotactic radiosurgery (SRS) has emerged as an effective and minimally-invasive treatment modality for irradiating either single or multiple intracranial structures in one clinical treatment setting. For this reason, we conducted a review of modern literature analyzing the efficacy of SRS in the management of patients with melanoma and renal cell carcinoma brain metastases. In our analysis we found SRS to be a safe, effective and attractive treatment modality for managing radioresistant brain metastases and highlighted the need for randomized trials comparing WBRT alone vs. SRS alone vs. WBRT plus SRS in treating patients with radioresistant brain metastases.
\end{abstract}

\section{Background}

The United States faces roughly 170,000 new cases of brain metastases each year, and this number is expected to increase as diagnostic technologies, such as magnetic resonance imaging (MRI), improve and as cancer patients acquire longer survival times [1-3]. The average survival of patients with brain metastases is one to two months with corticosteroid treatment alone, and four to seven months with whole brain radiotherapy (WBRT) alone [4]. The Radiation Therapy Oncology Group (RTOG) recursive partitioning analysis (RPA), which categorizes patients into one of three classes based on the patient's Karnofsky Performance Score (KPS), age, number of extracranial metastases, and status of primary cancer, with a higher class statistically indicating a worse prognosis, is the most common method for stratifying patients with brain metastases [4]. Out of all new brain metastases cases, approximately 1,200 to 5,100 originate from renal cell carcinoma annually, while roughly $10 \%$ originate from melanoma annually $[5,6]$.

\footnotetext{
* Correspondence: lee@ccnw.net

'Gamma Knife of Spokane, 910 W 5th Ave, Suite 102, Spokane, WA 99204, USA

${ }^{2}$ Cancer Care Northwest, 910 W 5th Ave, Suite 102, Spokane, WA 99204, USA Full list of author information is available at the end of the article
}

Both melanoma and renal cell carcinoma have a welldocumented tendency to cause brain metastases. Melanoma represents the third most common primary origin of brain metastases, following non-small-cell lung cancer and breast cancer [7]. The reported clinical occurrence of brain metastases is 8 to $46 \%$ in patients diagnosed with melanoma, and autopsy studies found brain metastases in 55 to $75 \%$ of these patients [7-10]. In a sizable autopsy series, the occurrence of brain metastases resulting from renal cell carcinoma was reported to be $11 \%[11,12]$. Unfortunately, the expected survival time for these patients is quite low and maximizing these patients' period of survival and comfort level is of great importance for clinicians. For untreated patients with intracranial melanoma, the median survival time is less than one month without treatment, and for treated patients the median survival time ranges from two to eight months $[7,9,13-17]$. Renal cell carcinoma patients with brain metastases have a reported mean survival time of three months if left untreated, and with treatment of WBRT the median survival time ranges from two to nine months [12,18-20]. Historically, brain metastases have been treated with WBRT, surgery or both, but increasingly 
stereotactic radiosurgery (SRS) is emerging as an attractive treatment modality.

SRS is a procedure that employs a high dose of extremely conformal radiation to treat lesions of a small volume in a single treatment session. Prior to treatment, a gadolinium enhanced magnetic resonance imaging is taken of the patient's head, within a coordinate frame if necessary. A neurosurgeon, radiation oncologist and medical physicist jointly analyze the size, location and shape of the metastases and develop appropriate treatment planning. There are three machine types commonly used for SRS delivery: the linear accelerator (LINAC), the CyberKnife and the Gamma Knife (GK). Studies have shown that the machine type used to apply SRS does not affect treatment outcome [21].

SRS is a desirable and effective treatment option for many patients with newly diagnosed radioresistant brain metastases due to its ability to improve local control, minimally-invasive nature and capability of treating multiple metastases in one setting. SRS has widened the range of treatable patients with radioresistant brain metastases by offering a treatment modality that addresses unresectable brain metastases and results in superior local control when compared to WBRT. We present a concise review of literature analyzing the efficacy of SRS in the management of patients with melanoma and renal cell carcinoma brain metastases.

\section{Review}

Cumulative research shows that SRS is an effective and safe treatment option for patients with radioresistant brain metastases. A recent study by Clarke et al. [22] found that GK SRS is a safe and effective treatment for patients with single radioresistant brain metastases, reporting a median survival of 8.1 months. A study by Jensen et al. [23] found SRS to be a well-tolerated and well suited treatment modality for patients with radioresistant brain metastases, reporting median survival rates of 7.4 months for patients with intracranial metastatic melanoma and 6.1 months for patients with intracranial metastatic renal cell carcinoma. In a study by Yu et al. [14], the overall median survival for patients with intracranial metastatic melanoma was 7 months from treatment of GK SRS, 9.1 months from the occurrence of brain metastasis and 46.7 months from the diagnosis of melanoma. A study by Mori et al. [7] found that SRS is an effective and safe treatment modality for patients with intracranial metastatic melanoma, and reported a median survival of seven months following SRS. A study by Noel et al. [12] found SRS to be an effective and efficient treatment for brain metastases originating from renal cell carcinoma, reporting an 11-month median survival. A study by Samlowski et al. [5] found SRS-based treatment for patients with intracranial metastatic renal cell carcinoma to result in excellent central nervous system (CNS) control, reporting a median survival of 10.1 months after diagnosis of brain metastases. In our experience at Gamma Knife of Spokane, patients with intracranial metastatic melanoma and intracranial metastatic renal cell carcinoma have benefited from stereotactic radiosurgery. We have published that patients with intracranial metastatic melanoma treated with SRS at Gamma Knife of Spokane have a median survival time of 9.7 months [24].

The SRS dose depends on the shape, position and size of the image-guided target. Reported optimal dose ranges are 15 to 22 Gy, with a median of 20 Gy [22]. The RTOG recommends that the maximum tolerated dose is $24 \mathrm{~Gy}$ for tumors whose diameters are less than or equal to $20 \mathrm{~mm}$, $18 \mathrm{~Gy}$ for tumors 21 to $30 \mathrm{~mm}$ in diameter and $15 \mathrm{~Gy}$ for tumors 31 to $40 \mathrm{~mm}$ in diameter [4]. The surrounding normal brain and outside organs are protected by the conformality of the technique. For example, in GK treatment, only $1 / 201$ th of the total radiation dose passes through the body on the way to the target site because there are 201 converging beams. It is only where the 201 beams converge on the metastatic brain tumor that the high dose is deposited. Software programs are also used to help target the radiation at optimal angles and doses to minimize radiation exposure to the rest of the body. Special care is taken when treating metastases around radiosensitive areas, such as the optic nerves or the brainstem.

SRS alone has established itself as an effective treatment modality for the treatment of radioresistant brain metastases, and the addition of WBRT remains controversial. Specifically, WBRT may benefit patients who are younger, have a higher KPS (equal to or greater than 70), or a lower Recursive Partitioning Analysis (RPA) class (1 or 2). A multiinstitutional Japanese phase III trial comparing SRS alone vs. SRS plus WBRT in treating patients with intracranial metastases did not find statistically significant differences in both survival and death as a result of neurologic causes between the two treatment arms; however, there was a significantly higher rate of intracranial failures (approximately $50 \%$ of patients after six months) in the SRS alone arm $[3,25]$. One of the arguments against WBRT is the possibility of neurocognitive decline as a side effect, but whether or not WBRT is detrimental to neurocognitive performance is inconclusive and more sensitive tests evaluating neurocognitive performance levels need to be conducted to determine if this is a valid potential side effect $[3,26]$. However, prospective data from a phase III randomized trial comparing SRS and SRS plus WBRT in patients with one to three brain metastases conducted at M.D. Anderson Cancer Center suggest that post-treatment decline in neurocognitive performance is more likely related to WBRT than to intracranial tumor progression [22]. The addition of WBRT to SRS has shown very limited effectiveness at treating radioresistant histologies, so the inclusion of WBRT should be decided on a case by case basis, based on the patient's informed decision on whether or not any possible marginal 
benefits gained from WBRT are worth the downsides of the treatment.

Further randomized trials comparing WBRT alone vs. WBRT plus SRS in treating patients with radioresistant brain metastases are needed because the decision of including WBRT with SRS in treating radioresistant brain metastases is still controversial. These studies are needed to help decisively determine the general standard of treatment for patients with radioresistant brain metastases.

\section{Conclusions}

Melanoma and renal cell carcinoma, considered to be radioresistant histologies, commonly cause brain metastases. SRS has proven to be an effective and safe treatment option for many cases involving these metastases. A prospective randomized trial that assesses the worth of adding WBRT in patients with intracranial metastatic melanoma or intracranial metastatic renal cell carcinoma treated with SRS is necessary. Evidence in the form of data from randomized trials comparing WBRT alone vs. SRS alone vs. WBRT plus SRS in treating patients with radioresistant brain metastases is needed in the future to further define optimal treatment approaches for each patient.

\section{Abbreviations}

CNS: central nervous system; GK: Gamma Knife; KPS: Karnofsky Performance Status; LINAC: linear accelerator; MRI: magnetic resonance imaging; RPA: recursive partitioning analysis; RTOG: radiation therapy oncology group; SRS: stereotactic radiosurgery; WBRT: whole-brain radiation therapy.

\section{Competing interests}

The authors declare no competing financial interests.

\section{Authors' contributions}

$\mathrm{PWH}, \mathrm{ALE}$ and $\mathrm{CML}$ reviewed relevant literature for this review and drafted the manuscript. WTL, JJD, RFK, ARM, BSC and SRT provided expertise relevant to this review and helped draft the manuscript. All authors read and approved the final manuscript.

\section{Acknowledgements}

We would like to acknowledge Eric Reynolds, Rachel Garman and Jill Adams, as well as the entire Gamma Knife of Spokane and Cancer Care Northwest research staff, for their contributions to this manuscript.

\section{Author details}

'Gamma Knife of Spokane, 910 W 5th Ave, Suite 102, Spokane, WA 99204, USA. ${ }^{2}$ Cancer Care Northwest, 910 W 5th Ave, Suite 102, Spokane, WA 99204, USA. ${ }^{3}$ Spokane Brain and Spine, 801 W 5th Ave, Suite 201, Spokane, WA 99204, USA. ${ }^{4}$ MacKay Meyer, MDs, 711 S Cowley St, Suite 201, Spokane, WA 99024, USA. ${ }^{5}$ Gamma Knife of Spokane and Cancer Care Northwest, 601 S. Sherman, Spokane, WA 99202, USA.

Received: 5 June 2012 Accepted: 15 August 2012

Published: 29 August 2012

\section{References}

1. Posner JB: Management of brain metastases. Rev Neurol (Paris) 1992, 148:477-487.

2. Patchell RA: The management of brain metastases. Cancer Treat Rev 2003, 29:533-540.

3. Manon R, O'Neill A, Knisely J, Werner-Wasik M, Lazarus HM, Wagner H, Gilbert M, Mehta M: Phase II trial of radiosurgery for one to three newly diagnosed brain metastases from renal cell carcinoma, melanoma, and sarcoma: an Eastern Cooperative Oncology Group study (E 6397). J Clin Oncol 2005, 23:8870-8876.

4. Elaimy AL, Mackay AR, Lamoreaux WT, Fairbanks RK, Demakas JJ, Cooke BS, Lee CM: Clinical outcomes of stereotactic radiosurgery in the treatment of patients with metastatic brain tumors. World Neurosurg 2011, 75:673-683.

5. Samlowski WE, Watson GA, Wang M, Rao G, Klimo P Jr, Boucher K, Shrieve $D C$, Jensen RL: Multimodality treatment of melanoma brain metastases incorporating stereotactic radiosurgery (SRS). Cancer 2007, 109: 1855-1862.

6. Marko NF, Angelov L, Toms SA, Suh JH, Chao ST, Vogelbaum MA, Barnet $\mathrm{GH}$, Weil RJ: Stereotactic radiosurgery as single-modality treatment of incidentally identified renal cell carcinoma brain metastases. World Neurosurg 2010, 73:186-193. discussion e29.

7. Mori Y, Kondziolka D, Flickinger JC, Kirkwood JM, Agarwala S, Lunsford LD: Stereotactic radiosurgery for cerebral metastatic melanoma: factors affecting local disease control and survival. Int J Radiat Oncol Biol Phys 1998, 42:581-589.

8. Bullard DE, Cox EB, Seigler HF: Central nervous system metastases in malignant melanoma. Neurosurgery 1981, 8:26-30.

9. Amer MH, Al-Sarraf M, Baker LH, Vaitkevicius VK: Malignant melanoma and central nervous system metastases: incidence, diagnosis, treatment and survival. Cancer 1978, 42:660-668.

10. Patel JK, Didolkar MS, Pickren JW, Moore RH: Metastatic pattern of malignant melanoma. A study of 216 autopsy cases. Am J Surg 1978, 135:807-810.

11. Saitoh H: Distant metastasis of renal adenocarcinoma. Cancer 1981, 48:1487-1491.

12. Noel G, Valery CA, Boisserie G, Cornu P, Hasboun D, Marc Simon J, Tep B, Ledu D, Delattre JY, Marsault C, Baillet F, Mazeron JJ: LINAC radiosurgery for brain metastasis of renal cell carcinoma. Urol Oncol 2004, 22:25-31.

13. Barth A, Wanek LA, Morton DL: Prognostic factors in 1,521 melanoma patients with distant metastases. J Am Coll Surg 1995, 181:193-201.

14. Yu C, Chen JC, Apuzzo ML, O'Day S, Giannotta SL, Weber JS, Petrovich Z: Metastatic melanoma to the brain: prognostic factors after gamma knife radiosurgery. Int J Radiat Oncol Biol Phys 2002, 52:1277-1287.

15. Lavine SD, Petrovich Z, Cohen-Gadol AA, Masri LS, Morton DL, O'Day SJ, Essner R, Zelman V, Yu C, Luxton G, Apuzzo ML: Gamma knife radiosurgery for metastatic melanoma: an analysis of survival, outcome, and complications. Neurosurgery 1999, 44:59-64. discussion 64-56.

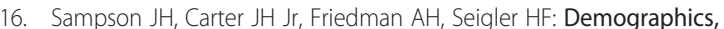
prognosis, and therapy in 702 patients with brain metastases from malignant melanoma. J Neurosurg 1998, 88:11-20.

17. Chen JC, Petrovich Z, O'Day S, Morton D, Essner R, Giannotta SL, Yu C, Apuzzo ML: Stereotactic radiosurgery in the treatment of metastatic disease to the brain. Neurosurgery 2000, 47:268-279. discussion 279-281.

18. Wronski M, Maor MH, Davis BJ, Sawaya R, Levin VA: External radiation of brain metastases from renal carcinoma: a retrospective study of 119 patients from the M. D. Anderson Cancer Center. Int J Radiat Oncol Biol Phys 1997, 37:753-759.

19. Gay PC, Litchy WJ, Cascino TL: Brain metastasis in hypernephroma. J Neurooncol 1987, 5:51-56.

20. Decker DA, Decker VL, Herskovic A, Cummings GD: Brain metastases in patients with renal cell carcinoma: prognosis and treatment. J Clin Oncol 1984, 2:169-173.

21. Andrews DW, Scott CB, Sperduto PW, Flanders AE, Gaspar LE, Schell MC, Werner-Wasik M, Demas W, Ryu J, Bahary JP, Souhami L, Rotman M, Mehta MP, Curran WJ Jr: Whole brain radiation therapy with or without stereotactic radiosurgery boost for patients with one to three brain metastases: phase III results of the RTOG 9508 randomised trial. Lancet 2004, 363:1665-1672.

22. Clarke JW, Register S, McGregor JM, Grecula JC, Mayr NA, Wang JZ, Li K, Gupta N, Kendra KL, Olencki TE, Cavaliere R, Sarkar A, Lo SS: Stereotactic radiosurgery with or without whole brain radiotherapy for patients with a single radioresistant brain metastasis. Am J Clin Oncol 2010, 33:70-74.

23. Jensen RL, Shrieve AF, Samlowski W, Shrieve DC: Outcomes of patients with brain metastases from melanoma and renal cell carcinoma after primary stereotactic radiosurgery. Clin Neurosurg 2008, 55:150-159.

24. Elaimy AL, Mackay AR, Lamoreaux WT, Fairbanks RK, Demakas JJ, Cooke BS, Peressini BJ, Holbrook JT, Lee CM: Multimodality treatment of brain metastases: an institutional survival analysis of 275 patients. World J Surg Oncol 2011, 9:69. 
25. Aoyama H, Shirato H, Tago M, Nakagawa K, Toyoda T, Hatano K, Kenjyo M, Oya N, Hirota S, Shioura H, Kunieda E, Inomata T, Hayakawa K, Katoh N, Kobashi G: Stereotactic radiosurgery plus whole-brain radiation therapy vs stereotactic radiosurgery alone for treatment of brain metastases: a randomized controlled trial. JAMA 2006, 295:2483-2491.

26. DeAngelis LM, Delattre JY, Posner JB: Radiation-induced dementia in patients cured of brain metastases. Neurology 1989, 39:789-796.

doi:10.1186/1477-7819-10-176

Cite this article as: Hanson et al:: A concise review of the efficacy of

stereotactic radiosurgery in the management of melanoma and renal cell carcinoma brain metastases. World Journal of Surgical Oncology 2012 10:176.

\section{Submit your next manuscript to BioMed Central and take full advantage of:}

- Convenient online submission

- Thorough peer review

- No space constraints or color figure charges

- Immediate publication on acceptance

- Inclusion in PubMed, CAS, Scopus and Google Scholar

- Research which is freely available for redistribution 